\title{
Incentivising innovation in antibiotic drug discovery and development: progress, challenges and next steps
}

\author{
Victoria L Simpkin ${ }^{1}$, Matthew J Renwick ${ }^{1}$, Ruth Kelly ${ }^{1}$ and Elias Mossialos ${ }^{1,2}$
}

Political momentum and funding for combatting antimicrobial resistance (AMR) continues to build. Numerous major international and national initiatives aimed at financially incentivising the research and development (R\&D) of antibiotics have been implemented. However, it remains unclear how to effectively strengthen the current set of incentive programmes to further accelerate antibiotic innovation. Based on a literature review and expert input, this study first identifies and assesses the major international, European Union, US and UK antibiotic R\&D funding programmes. These programmes are then evaluated across market and public health criteria necessary for comprehensively improving the antibiotic market. The current set of incentive programmes are an important initial step to improving the economic feasibility of antibiotic development. However, there appears to be a lack of global coordination across all initiatives, which risks duplicating efforts, leaving funding gaps in the value chain and overlooking important AMR goals. This study finds that incentive programmes are overly committed to early-stage push funding of basic science and preclinical research, while there is limited late-stage push funding of clinical development. Moreover, there are almost no pull incentives to facilitate transition of antibiotic products from early clinical phases to commercialisation, focus developer concentration on the highest priority antibiotics and attract large pharmaceutical companies to invest in the market. Finally, it seems that antibiotic sustainability and patient access requirements are poorly integrated into the array of incentive mechanisms.

The Journal of Antibiotics (2017) 70, 1087-1096; doi:10.1038/ja.2017.124; published online 1 November 2017

\section{INTRODUCTION}

Antimicrobial resistance (AMR) is a global health crisis now. At the current rate of emergence and spread of AMR, annual loss of life is expected to reach 10 million deaths by 2050 with an estimated economic cost of $\$ 100$ trillion. ${ }^{1}$ Effectively combating AMR requires a multifaceted approach that facilitates sustainable and equitable use of antimicrobials, thwarts the spread of infectious disease, preserves existing antimicrobial therapies and fosters innovation of new therapies and diagnostic tools. A critical component of the AMR solution is the development of truly novel antibiotic drugs to cover the diminishing effectiveness of existing antibiotics that are relied on every day for essential clinical care. However, due to a variety of inherent market failures, the present business model for antibiotics has not adequately responded to the growing demand for innovation. ${ }^{2-4}$

At first glance, it may seem that the antibiotic development pipeline has been substantially reinvigorated in response to the growing emergency. The Pew Trust estimates that as of March 2017, there are 39 antibiotics in Phases I to III of the development pipeline. However, further investigation reveals that the current antibiotic pipeline is not robust enough to address the current and projected clinical need. ${ }^{5,6}$ First, the success rates of moving an antibiotic through the different clinical phases suggests that of the 39 drugs in development, only $13(33 \%)$ will translate into a marketable product. $^{7}$ Second, most new antibiotics do not have the novel mechanisms of action or novelty in chemical matter targeting wellvalidated targets, which are necessary to significantly ensure effectiveness against resistant pathogens. ${ }^{8}$ Many of the products in the pipeline are redevelopments or combinations of existing compounds. Third, many of these drugs do not target the highest priority antibiotic resistant pathogens. The Pew Trust analysis shows that only $31 \%$ of drugs in development would be active against an ESKAPE pathogen and $33 \%$ would be active against a US Centre for Disease Control urgent threat pathogen. ${ }^{6}$

Scientific and clinical advancements in antibiotic development are inherently challenging, particularly relative to other therapeutic fields. Many large capital companies have exited the antibiotic space in favour of more profitable therapeutic ventures. Small- and mediumsized enterprises (SMEs) have attempted to fill this void but generally lack the capital and resources to undertake intensive and long-term research and development (R\&D). ${ }^{9,10}$ Consequently, the low hanging fruit of antibiotic development, such as compound redevelopments and combinations, has been tapped. This leaves behind the complex and expensive task of discovering and developing truly novel mechanisms of action that are effective against the most resistant pathogens. ${ }^{11}$ Some companies are choosing to focus development efforts on alternatives to antibiotics such as antibodies, probiotics, lysins and bacteriophages.

${ }^{1}$ Department of Health Policy, London School of Economics and Political Science, London, UK and ${ }^{2}$ Institute of Global Health Innovation, Imperial College London, London, UK Correspondence: Professor E Mossialos, Department of Health Policy, London School of Economics and Political Science, Houghton Street, London WC2A 2AE, UK. E-mail: E.A.MOSSIALOS@LSE.AC.UK

Received 13 July 2017; revised 4 September 2017; accepted 9 September 2017; published online 1 November 2017 


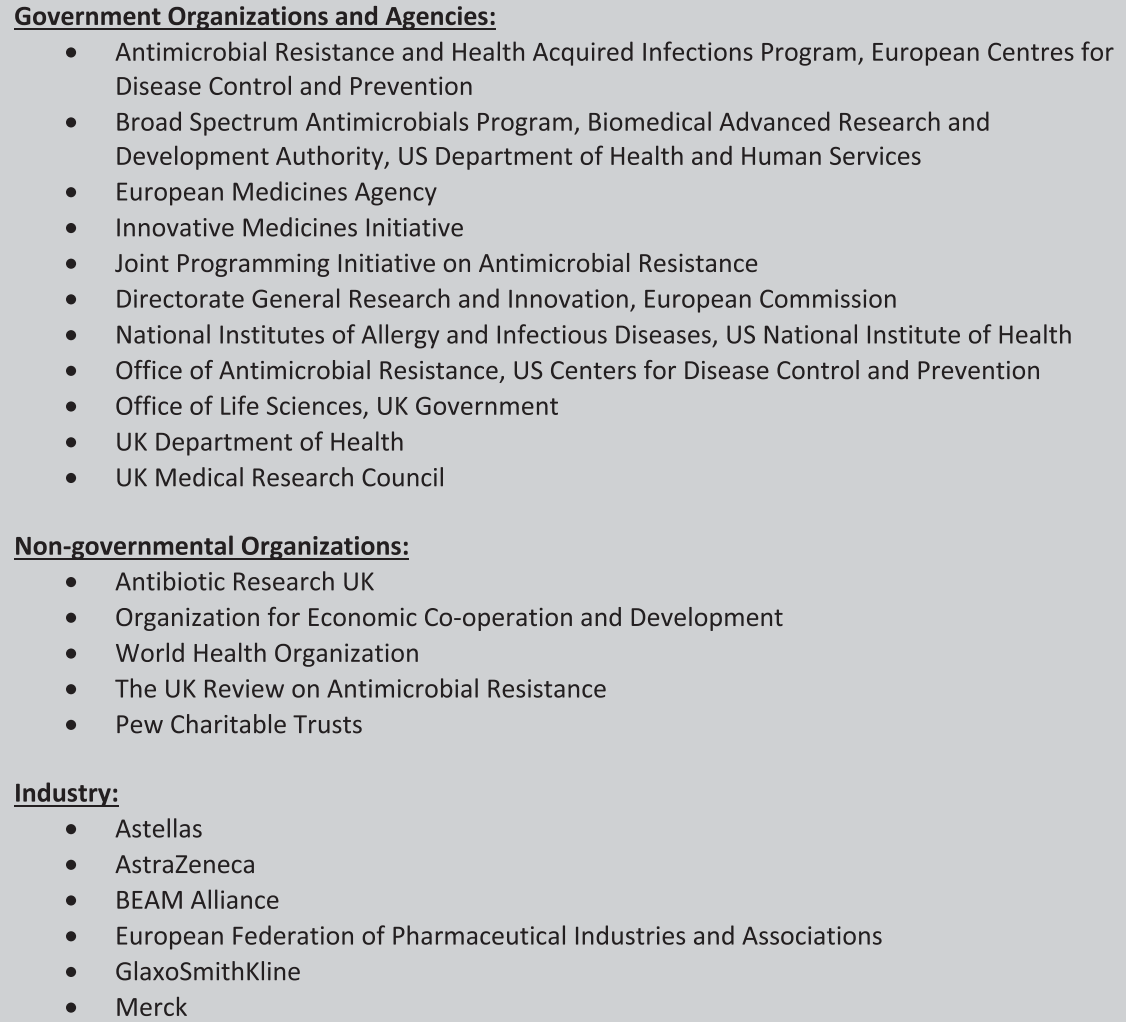

Figure 1 List of organisations that provided expert input on the compilation and basic assessment of identified R\&D initiatives.

During the past decade, over 50 major international and national initiatives aimed at incentivising antibiotic R\&D have been implemented such as the Joint Programming Initiative on Antimicrobial Resistance (JPIAMR), the Innovative Medicines Initiative's (IMI's) New Drugs for Bad Bugs (ND4BB) programme, Biomedical Advanced Research and Development Authority's (BARDA) Broad Spectrum Antimicrobials Program and Combating Antibiotic Resistant Bacteria Biopharmaceutical Accelerator (CARB-X). ${ }^{8}$ Political momentum for combatting AMR continues to build. Coming out of the 2016 G20 Meeting and the United Nations General Assembly's High-Level Meeting on AMR, political leaders have committed to continued actions that foster antibiotic R\&D. ${ }^{12,13}$ In March 2017, the UN announced the establishment of an Inter-Agency Coordination Group on AMR to provide practical guidance to ensure sustainable, effective global action to address AMR with a mandate to report back on progress to the United Nations General Assembly 73rd session running from September 2018 to September 2019. ${ }^{14}$ It remains unclear, however, how to most effectively capitalise on the existing $\mathrm{R} \& \mathrm{D}$ incentive programmes.

In a 2015 review article in The Journal of Antibiotics, Renwick et al. ${ }^{15}$ presented a conceptual framework for evaluating incentive programmes and assisting policy makers in selecting appropriate incentives. The framework incorporates market criteria necessary for attracting and supporting investment in antibiotic R\&D and public health objectives that attend to sustainability and patient access goals. In the present study, we apply this conceptual framework to analyse the major global and European Union R\&D initiatives, as well as national R\&D programmes in the United States and United Kingdom. We then identify gaps in the current initiative provisions and provide recommendations for how the global community can further improve the market for antibiotics in a way that is sustainable and equitable.

\section{METHODOLOGY}

Our research methodology involved three phases: a literature review, expert input and initiative analysis. Owing to the sheer number of initiatives worldwide that target antibiotic $\mathrm{R} \& \mathrm{D}$, this review was limited to initiatives at multi-lateral, EU, US, and UK levels. The US and UK are two of the most active countries with regards to developing and implementing dedicated $R \& D$ initiatives on AMR and thus were the focus of our national level analysis. This study further focuses on the initiatives that provide direct antibiotic $R \& D$ incentives backed by funding or regulatory support.

\section{Literature review}

Through a semi-systematic literature review we identified current and proposed policy initiatives that foster R\&D. We reviewed relevant peer-reviewed articles with the use of MEDLINE (PubMed), Embase (Ovid) and Web of Science. Search terms included: 'antibiotic', 'antimicrobial', 'antibacterial', 'resistance', 'resistant', 'alternative', 'diagnostic', 'devices', 'research', 'development', 'incentive', 'policy', 'mechanism', 'business model', 'strategy' and 'instrument'. The search was restricted to papers published in the last 5 years, in English, and either comments, editorials, journal articles, reviews or systematic reviews. Additional non-peer reviewed literature was included in this report and identified through a Google search and from citations in several key papers and publication archives on relevant websites. 


\section{Expert opinion}

Once an initial compilation of initiatives had been established, we solicited expert input to ensure that we had correct information and had not missed any pertinent initiatives (Figure 1). Experts related to an initiative provided feedback regarding their initiative's priorities, operational programmes, R\&D incentive mechanisms and funding. Further telephone interviews were conducted with select experts to learn more about particular major initiatives. The analyses and discussion of this report are based on the authors' assessment and do not necessarily reflect the opinions of the experts consulted in the process.

\section{Initiative assessment}

All initiatives were then analysed using an assessment framework for antibiotic R\&D incentive packages developed by Renwick et al. ${ }^{15}$ The framework can be broken down into three successive levels that examine economic, public health and feasibility criteria (Figure 2). The first step involves evaluating an initiative's core economic incentives that address key criteria necessary for rebalancing the antibiotics market. This core incentive package must improve the net present value (NPV) of antibiotic project development, make antibiotic development possible for SMEs, encourage participation of large pharmaceutical companies and foster synergy among all stakeholders in the market. NPV is a profitability metric that sums a project's total revenues and costs, corrected for the time value of money and the project's risk of failure. The second level of assessment examines an initiative's ability to address public health goals pertaining to clinical need, antibiotic sustainability and patient access to necessary antibiotics. The last step considers the package's implementation and operational feasibility. This final step of evaluation will not be applied in this assessment given that we are concerned with initiatives that have already been implemented.

\section{RESULTS}

The results section will present short case studies of each of the initiatives that were assessed. We provide a summary of an initiative's



Figure 2 Framework evaluation. background, incentive package, targeted $\mathrm{R} \& \mathrm{D}$ barriers and funding (Supplementary File). In addition, we offer a brief analysis of the initiatives according to our framework assessment (Table 1).

\section{Multi-lateral initiatives}

Joint Programming Initiative on Antimicrobial Resistance. The JPIAMR is an international effort focused on streamlining and coordinating research in an effort to combat AMR. ${ }^{16}$ It was established in 2011 and currently has 22 member states. It provides international coordination to direct national funding towards research projects that fill key knowledge gaps in AMR. The first call to action specifically focused on 'innovative approaches to address antibacterial resistance'. ${ }^{17}$

To date, the total budget of supported projects is $\mathfrak{£} 41.65$ million, although this extends more broadly than antibiotic R\&D. Push incentives are provided in the form of direct research funding and an international forum for research collaboration allowing the potential to share novel research, minimise duplication and pool funding resources. The projects mainly target basic and preclinical research, primarily benefiting academics. ${ }^{16}$ Athough the JPIAMR as a whole promotes antibiotic conservation and patient access, this focus on the early stages of the value chain means that these incentives do not particularly reinforce stewardship programmes or patient access to developed antibiotics down the line.

Global Antibiotic Research and Development Partnership. Global Antibiotic Research and Development Partnership (GARDP), a notfor-profit entity, was launched in May 2016. It is now in its incubation phase hosted by the Drugs for Neglected Diseases initiative in collaboration with the World Health Organisation. ${ }^{18}$ The aim is to develop novel antibiotics, focusing on R\&D gaps in which neither industry nor academia are currently engaging, as well as to promote their responsible use and ensure equitable access.

GARDP has received seed funding and pledges exceeding $€ 5$ million for 2016-2018. It aims to target all stages of the value chain from basic research to commercialisation. The partnership model allows pooling of expertise to develop priority target product profiles. It offers push mechanisms in the form of direct funding, but will also pilot the use of alternative incentive models that contribute to conservation of, and access to, new antibiotics. These include pull mechanisms such as milestone prizes and delinking the cost of $\mathrm{R} \& \mathrm{D}$ from volumebased sales and prices of antibiotics. ${ }^{18}$ The strong emphasis on collaboration with stakeholders encourages synergy across the antibiotic market.

Combating Antibiotic Resistant Bacteria Biopharmaceutical Accelerator. CARB-X, a global -private partnership, was launched in July 2016 with the mission to accelerate a diverse portfolio of at least 20 highquality antibacterial products towards clinical development. ${ }^{19} \mathrm{CARB}-\mathrm{X}$ has currently received a $\$ 250$ million commitment from BARDA over 5 years with contributory funds from the Wellcome Trust and the AMR Centre in the UK, with total funding of $\$ 350$ million over 5 years. MassBio and the California Life Sciences Institute, two life science accelerators, alongside other partners will provide support for early-stage antibiotic development. Although the leadership is initially trans-Atlantic, the structure is designed to accept additional partners from other regions.

CARB-X predominantly uses push incentives by providing matching funding and technical assistance, including business support, mentoring and research support services, to developers for defined projects. It supports projects targeting high-priority medical needs 
Table 1 Overview of the analysis of initiatives supporting antibiotic R\&D

\begin{tabular}{|c|c|c|c|c|c|c|}
\hline Initiative & Improves NPV & $\begin{array}{l}\text { Enables } \\
\text { participation of } \\
\text { SMEs }\end{array}$ & $\begin{array}{l}\text { Encourages } \\
\text { participation of } \\
\text { large cap firms }\end{array}$ & $\begin{array}{l}\text { Facilitates } \\
\text { cooperation and } \\
\text { synergy }\end{array}$ & $\begin{array}{l}\text { Directly } \\
\text { incentivizes } \\
\text { antibiotic } \\
\text { conservation and } \\
\text { patient access }\end{array}$ & $\begin{array}{l}\text { Targets specific } \\
\text { high-priority } \\
\text { medical needs }\end{array}$ \\
\hline \multicolumn{7}{|l|}{ Multi-lateral } \\
\hline JPIAMR & $\checkmark$ & $x$ & $x$ & $\checkmark$ & $x$ & $\checkmark$ \\
\hline 1st Joint Call & $\checkmark$ & $x$ & $x$ & $\checkmark$ & $x$ & $\checkmark$ \\
\hline 2nd Joint Call & $\checkmark$ & $x$ & $x$ & $\checkmark$ & $x$ & $\checkmark$ \\
\hline 3rd Joint Call & $\checkmark$ & $x$ & $x$ & $\checkmark$ & $x$ & $\checkmark$ \\
\hline 4th Joint Call & $\checkmark$ & $\checkmark$ & $x$ & $\checkmark$ & $x$ & $\checkmark$ \\
\hline 5th Joint Call & $\checkmark$ & $x$ & $x$ & $\checkmark$ & $\checkmark$ & $\checkmark$ \\
\hline GARDP & $\checkmark$ & $\checkmark$ & $\checkmark$ & $\checkmark$ & $\checkmark$ & $\checkmark$ \\
\hline CARB-X & $\checkmark$ & $\checkmark$ & $\checkmark$ & $\checkmark$ & $x$ & $\checkmark$ \\
\hline EDCTP & $\checkmark$ & $\checkmark$ & $\checkmark$ & $\checkmark$ & $\checkmark$ & $\checkmark$ \\
\hline GAMRIF & $\checkmark$ & $\checkmark$ & TBC & $\checkmark$ & TBC & $\checkmark$ \\
\hline \multicolumn{7}{|l|}{ European Union } \\
\hline DG-RTD & $\checkmark$ & $\checkmark$ & $\checkmark$ & $\checkmark$ & $x$ & $\checkmark$ \\
\hline IMI: ND4BB & $\checkmark$ & $x$ & $\checkmark$ & $\checkmark$ & $x$ & $\checkmark$ \\
\hline ND4BB: TRANSLOCATION & $\checkmark$ & $x$ & $\checkmark$ & $\checkmark$ & $x$ & $\checkmark$ \\
\hline ND4BB: ENABLE & $\checkmark$ & $\checkmark$ & $\checkmark$ & $\checkmark$ & $x$ & $\checkmark$ \\
\hline ND4BB: COMBACTE & $\checkmark$ & $x$ & $\checkmark$ & $\checkmark$ & $x$ & $\checkmark$ \\
\hline ND4BB: COMBACTE-CARE & $\checkmark$ & $x$ & $\checkmark$ & $\checkmark$ & $x$ & $\checkmark$ \\
\hline ND4BB: COMBACTE-MAGNET & $\checkmark$ & $x$ & $\checkmark$ & $\checkmark$ & $x$ & $\checkmark$ \\
\hline ND4BB: iABC & $\checkmark$ & $x$ & $\checkmark$ & $\checkmark$ & $x$ & $\checkmark$ \\
\hline InnovFin ID & $\checkmark$ & $\checkmark$ & $x$ & $x$ & $x$ & $\checkmark$ \\
\hline \multicolumn{7}{|l|}{ United States } \\
\hline $\mathrm{NIH}$ & $\checkmark$ & $\checkmark$ & $\checkmark$ & $\checkmark$ & $x$ & $\checkmark$ \\
\hline BARDA & $\checkmark$ & $\checkmark$ & $\checkmark$ & $\checkmark$ & $x$ & $\checkmark$ \\
\hline BARDA BSA Program & $\checkmark$ & $\checkmark$ & $\checkmark$ & $\checkmark$ & $x$ & $\checkmark$ \\
\hline BARDA/GSK Partnership & $\checkmark$ & $x$ & $\checkmark$ & $\checkmark$ & $x$ & $\checkmark$ \\
\hline BARDA/AstraZeneca Partnership & $\checkmark$ & $x$ & $\checkmark$ & $\checkmark$ & $x$ & $\checkmark$ \\
\hline \multicolumn{7}{|l|}{ United Kingdom } \\
\hline Research Councils UK & $\checkmark$ & $x$ & $x$ & $\checkmark$ & $x$ & $\checkmark$ \\
\hline $\begin{array}{l}\text { Cross Research Council AMR } \\
\text { Initiative }\end{array}$ & $\checkmark$ & $x$ & $x$ & $\checkmark$ & $x$ & $\checkmark$ \\
\hline Global Challenge Research Fund & $\checkmark$ & $x$ & $x$ & $\checkmark$ & $x$ & $\checkmark$ \\
\hline Newton Fund & $\checkmark$ & $x$ & $x$ & $\checkmark$ & $\checkmark$ & $\checkmark$ \\
\hline NIHR & $\checkmark$ & $\checkmark$ & $x$ & $\checkmark$ & $x$ & $\checkmark$ \\
\hline \multicolumn{7}{|l|}{ Regulatory bodies } \\
\hline EMA & $\checkmark$ & $x$ & $\checkmark$ & $\checkmark$ & $x$ & $\checkmark$ \\
\hline FDA & $\checkmark$ & $x$ & $\checkmark$ & $\checkmark$ & $x$ & $\checkmark$ \\
\hline
\end{tabular}

Abbreviations: AMR, antimicrobial resistance; BARDA, Biomedical Advanced Research and Development Authority; BSA, Broad Spectrum Antimicrobials; CARB-X, Combating Antibiotic Resistant Bacteria Biopharmaceutical Accelerator; DG-RTD, Directorate-General for Research and Innovation, European Commission; EDCTP, European and Developing Countries Clinical Trials Partnership; EMA, European Medicines Agency; FDA, US Food and Drug Administration; GAMRIF, Global Antimicrobial Resistance Innovation Fund; GARDP, Global Antibiotic Research and Development Partnership; IMI, Innovative Medicines Initiative; JPIAMR, Joint Programming Initiative on Antimicrobial Resistance; ND4BB, New Drugs for Bad Bugs; NIHR, National Institute for Health Research; $\mathrm{NIH}$, National Institutes of Health; NPV, net present value; R\&D, research and development; SME, small- and medium-sized enterprise.

from the basic and preclinical research stage up to phase 1 clinical trials. ${ }^{20}$ In its first year, the CARB-X portfolio will primarily focus on therapeutics treating Gram-negative bacteria on the Serious or Urgent Threat List prepared by the Centre for Disease Control. ${ }^{21}$ The services are available to product developers from any country, and both public and private organisations can apply. CARB-X has announced the initial portfolio of companies; they have selected 11 companies (8 based in the US and 3 in the UK) to be supported with \$24 million. There may be up to a further $\$ 24$ million in milestone-based additional payments over 3 years. ${ }^{22}$ Similar to other programmes that provide only push funding to the initial stages of R\&D, stewardship and patient access programmes are not explicitly supported by CARB$\mathrm{X}$ incentives.
European and Developing Countries Clinical Trials Partnership. The European and Developing Countries Clinical Trials Partnership (EDCTP) was formed in 2003, followed by EDCTP2 in 2014, and is an evolving public-public partnership between 14 European countries, 14 African countries and the EU, in collaboration with the pharmaceutical industry. It aims to support the acceleration of new clinical trial interventions to prevent and treat HIV/AIDs, tuberculosis, malaria and neglected infectious diseases, including certain bacterial infections, in sub-Saharan Africa. ${ }^{23}$ The funding for EDCTP2 (2014$2024)$ is estimated to be $€ 2$ billion, double the funding of the EDCTP (2003-2013).

The EDCTP provides a push incentive in the form of direct funding for $R \& D$ resources and infrastructure required to move a drug 
candidate through the clinical development phases. It targets all clinical trial phases I to IV and has been successful in fostering R\&D of antibiotics and related products as evidenced by its extensive drug development portfolio. It is unclear how, if at all, the EDCTP pulls potential novel antibiotics through the market approval stages and commercialisation process. Furthermore, the industry partnership is heavily weighted towards large capital pharmaceutical companies rather than SMEs. The EDCTP's ultimate goal of improving access to effective treatments aligns well with current public health priorities but the initiative does not have direct means to facilitate the appropriate use of antibiotics that are produced through the initiative.

Global Antimicrobial Resistance Innovation Fund. The UK AMR Review recommended that significant investment in a fund was needed to tackle AMR globally. ${ }^{24}$ In late 2016, an expert advisory board was appointed to support Global Antimicrobial Resistance

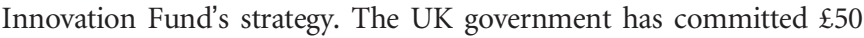
million until 2021 to work with global public and private partners to fund innovative initiatives to tackle drug-resistant infections following a One Health approach. The Global Antimicrobial Resistance Innovation Fund will focus on organisations struggling to access traditional financing routes, for example, SMEs. Initially, the UK is investing $\mathfrak{E} 10$ million with matched funding from China and private businesses. ${ }^{25}$ How the remaining $\mathfrak{E} 40 \mathrm{~m}$ is to be invested is yet to be announced.

\section{European Union initiatives}

Directorate-General for Research and Innovation, European Commission. The Directorate-General for Research and Innovation, European Commission (DG-RTD) is one of the largest funding bodies supporting the $\mathrm{R} \& \mathrm{D}$ of antibiotics, alternative medicines and diagnostic tools. ${ }^{26}$ The funding comes from Framework Program 6, Framework Program 7 (FP7) and Framework Program 8 known as Horizon 2020. Two of the largest funding programmes operating under the partial governance of the DG-RTD are the IMI and EDCTP. The DG-RTD has committed $€ 317$ million to the IMI for antibiotic R\&D through the ND4BB Program and $€ 683$ million has been committed to the EDCTP2 between 2014 and 2024. The DG-RTD also funds individual R\&D projects beyond their dedicated AMR programmes. Between 2007 and 2013, the DG-RTD spent $€ 235$.6 million on therapeutic and diagnostic projects separate from the IMI and EDCTP. ${ }^{27}$

The DG-RTD predominantly uses push incentives such as direct project funding, and research grants and fellowships. It provides specific funding opportunities for SME ventures such as the SME Instrument. The funded projects, however, vary in scope and size, making it difficult to accurately assess the effectiveness of the individual initiatives. There is the Horizon 2020 Better Use of Antibiotics $€ 1 \mathrm{~m}$ Prize for developing a rapid-point-of-care test to identify patients with upper respiratory tract infections that can be treated without antibiotics which, although an interesting pull incentive, is a relatively small reward. ${ }^{28}$ The DG-RTD brings together key stakeholders throughout the antibiotic value chain.

ND4BB and IMI. Launched in 2008, the IMI is a public-private partnership between the EU and the European Federation of Pharmaceutical Industries and Associations. ${ }^{29}$ The second iteration of IMI was launched in 2014. The ND4BB programme is an IMI partnership established in 2012, tasked with improving the discovery and development of novel antibiotics for humans. ${ }^{30}$ The ND4BB comprised seven core projects with a total budget of $€ 700$ million, of which $€ 317$ is contributed by the European Commission's FP7 and
$€ 345$ is in-kind contributions from the European Federation of Pharmaceutical Industries and Associations.

This initiative targets all aspects of the antibiotic value chain and the public-private partnership model employed throughout seems to be effective at pooling resources, facilitating collaboration among key stakeholders in the development process and sharing the financial risk of R\&D outlays. With the exception of ENABLE and DRIVE-AB, ND4BB programmes primarily engage large pharmaceutical companies and not SMEs. ${ }^{31}$

InnovFin infectious disease finance facility. Launched in 2014, InnovFin Infectious Diseases is a financial instrument jointly developed by the European Commission and European Investment Bank. InnovFin Infectious Disease offers loans between $€ 7.5$ and $€ 75$ million for the development of innovative vaccines, drugs, medical and diagnostic devices, and novel research infrastructures for combatting infectious diseases. ${ }^{32}$ It is a risk-sharing initiative, as the loan is only paid back if the project is successful.

In theory, this late-stage push funding is available to large pharmaceutical companies, SMEs, research outfits and universities and non-profit entities. Eligible projects, however, must have surpassed the initial basic research and preclinical phases of development, which may block the participation of smaller organisations without the capital for initial testing. Furthermore, given the significant cost of clinical trials the loan sizes may be considered unsatisfactory support by potential loan applicants. ${ }^{8,33}$ It is unclear how the InnovFin Infectious Disease Eligibility Committee selects projects and there is a risk that these projects do not reflect global priorities on AMR.

\section{United States initiatives}

National Institutes of Health. The National Institute of Allergy and Infectious Diseases is the primary government agency within the National Institutes of Health $(\mathrm{NIH})$ that funds antibiotic R\&D from basic research through to clinical development. It provides access to its vast network of R\&D infrastructure, scientific expertise, and public and private partners. Over the past 5 years, the NIH allocated $\$ 341$ million ( $1.2 \%$ of the NIH's budget) annually on average to projects on $\mathrm{AMR}^{3,24}$

The NIH's pipeline levers are heavily push-based, including direct project grants and research grants and fellowships. The Antimicrobial Resistance Diagnostic Challenge, a joint effort between the NIH and BARDA, awards $\$ 20$ million for the development of a rapid diagnostic test that can improve treatment of drug resistant infections. Although the diagnostic prize is a notable step towards outcome-based pull mechanisms, it remains to be seen whether this is a large enough incentive. $^{8}$

Biomedical Advanced Research and Development Authority. BARDA, within the Office of the Assistant Secretary for Preparedness and Response in the US Department of Health and Human Services, is tasked with enhancing development and purchasing of critical vaccines, drugs, therapies and diagnostic tools intended for public health emergencies. BARDA established the Broad Spectrum Antimicrobials programme in April 2010, to develop novel antibacterial and antiviral drugs to treat or prevent diseases caused by biological threats. ${ }^{34}$ Their 2016 fiscal year budget was $\$ 182$ million. ${ }^{8}$

BARDA's Broad Spectrum Antimicrobials uses innovative business models to establish public-private partnerships with industry, both large pharmaceutical companies and SMEs. ${ }^{35}$ As the programme began, it has assisted four candidate antibiotics from preclinical stages to Phase III clinical trials and another candidate to late stage Phase I 
clinical trials. BARDA has established flexible cost-sharing partnerships with GSK (\$200 million over 5 years) and AstraZeneca (\$170 million over 5 years) to fund an entire portfolio of projects. ${ }^{34,36}$ Although the initial focus on defensive- and emergency-related drugs may have limited the scope of its antibiotic R\&D agenda, a 2014 presidential executive order decoupled the need for BARDA-funded antibiotic programmes to address both public health and biodefense indications. ${ }^{35,37}$

\section{United Kingdom initiatives}

UK research councils. The UK Research Councils are responsible for several key antibiotic R\&D initiatives including the Cross Research Council Initiative, the Global Challenge Fund and the Newton Fund.

Cross Research Council AMR initiative. The UK Cross Research Council Initiative was founded in 2014 and involves all seven research councils, using a thematic One Health multidisciplinary approach to tackle AMR. ${ }^{38}$ It has subsequently expanded to include other UK funders such as the UK Department of Health. This initiative offers a range of direct funding to academics from small innovation grants to

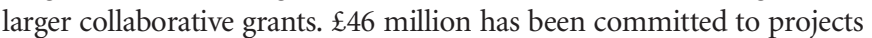
to date plus an additional $\mathfrak{E} 2.25$ million via the Medical Research Foundation AMR studentship programme. The Medical Research Council is currently leading a $£ 10 \mathrm{~m}$ call for proposals to tackle AMR, focusing on interdisciplinary research relevant to low- and middleincome countries.

This initiative uses push incentives in the form of direct funding, targeting the early stages of the value chain (basic and preclinical research). This collaborative approach, breaking down the traditional health science R\&D silos, allows the sharing of information and resources between relevant stakeholders. However, the early stage push funding does little to incentivise developers to commit to stewardship and patient access goals.

Global challenge research fund. The Global Challenge Research Fund is a $\mathfrak{E} 1.5$ billion fund, established in 2016 , to support research that addresses the challenges faced by developing countries. Topics under discussion include AMR. The UK Cross Research Council AMR initiative that is focused on low- and middle-income countries will utilise some of this funding. ${ }^{39}$

Newton fund. The Newton Fund, founded in 2014, is an initiative intended to strengthen research and innovation partnerships between the UK and partner countries. It has received funding ear-marked for AMR from the UK research councils ( $£ 6.75$ million), China ( $£ 4.5$ million), India ( $£ 2$ million) and South Africa ( $£ 0.25$ million)—with matched funding from participating countries. Further partnerships are in development with China, India, South Africa and Brazil. ${ }^{40}$

The Newton Fund projects form valuable scientific relationships and resource channels between the UK and low- and middle-income countries, where a significant proportion of the AMR health burden exists. They address One Health priorities and some aspects of highpriority medical need and antibiotic stewardship. The funding is dedicated to academics, therefore, the initiatives do not actively engage SMEs or large pharmaceutical firms.

National Institute for Health Research. The National Institute for Health Research (NIHR) is a UK government body that receives Department of Health funding to direct and coordinate translational research programmes that benefit patients in England's NHS. AMR is one of the key priorities for the NIHR and there are a number of ongoing programmes. ${ }^{41}$ NIHR Biomedical Research Centres are partnerships between an academic partner and an NHS host, which aim to provide bench-to-bedside translational medicine; 4 out of the 20 Biomedical Research Centres' focus on infection. Health Protection Research Units, usually between universities and Public Health England, have allocated approximately $\mathfrak{E} 8$ million (2014-2019) to two AMR Units. Furthermore, NIHR set out an AMR Themed Call in

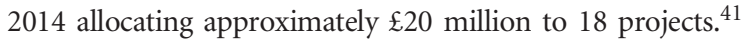

These initiatives use push incentives in the form of direct funding. They tend to target the earlier stages of the value chain but there is a focus on bench to bedside translational medicine and applied research.

\section{Regulatory body initiatives}

European Medicines Agency. As the central drug regulatory body for the EU, the European Medicines Agency (EMA) is responsible for the market authorisation of antibiotics submitted through their centralised procedure on behalf of the European member states. The EMA employs a number of lego-regulatory pull mechanisms to expedite the market approval of novel antibiotics such as granting conditional market authorisation for drugs that meet unmet medical needs. ${ }^{42}$ Earlier market entry may improve the revenue potential of a novel antibiotic as the developer can take advantage of a longer effective market exclusivity period. Although the faster approval periods can increase access to needed antibiotics, it may come at the cost of ensuring a high standard of safety and efficacy. ${ }^{15}$ SMEs may find these mechanisms do little to help them move through the expensive clinical phases of development.

US Food and Drug Administration. The US Food and Drug Administration is responsible for the market authorisation of antibiotics in the United States and uses lego-regulatory pull strategies to accelerate novel antibiotic development, targeting the later stages of the value chain. The 2012 Generating Antibiotic Incentives Now Act allows Qualified Infectious Disease Product designations to be granted to unique drugs, which can receive priority review, fast-tract designation, as well as a longer market exclusivity period. ${ }^{43} \mathrm{~A}$ further initiative proposed under the 21st Century Cures Act is a Limited Population Antibacterial Drug programme, which would provide a new approval pathway to streamline the process of antibiotic development, allowing faster access to antibiotics for patients with serious bacterial infections lacking appropriate treatment options. ${ }^{44}$ The lego-regulatory policies may not benefit SMEs whom often lack the capital reserve required to reach the clinical trial assessment stages.

\section{DISCUSSION}

It promising to see that there are multiple initiatives that offer valuable incentives such as direct funding, $\mathrm{R} \& \mathrm{D}$ resources, open-source collaboration programmes, financial debt instruments and regulatory assistance (Figure 3). All these incentives work together to reduce the NPV of antibiotic R\&D. However, as seen in Figure 3, there is an uneven distribution of incentives employed by R\&D initiatives. Most of these incentives are push mechanisms that provide upfront payments or indirect cost savings during the R\&D process of basic research and preclinical and clinical trials. Table 2 illustrates this issue from a different angle; $71 \%$ of initiatives offer strictly push incentives. Although push incentives are important and positively impact NPV, it is recognised that to produce novel antibiotics a continuum of funding is needed across the entire antibiotic development value chain from basic research through to marketing. This issue is reflected in the antibiotic development pipeline, which has few products in phases 2 and 3 of clinical trials, and it is uncertain if they will translate into antibiotics available on the market. ${ }^{11}$ 
There is even an imbalance in the distribution of push funding across the development value chain. We found that most initiatives, including the JPIAMR, CARB-X, DG-RTD, NIH, UK Cross Research Council, Newton Fund and NIHR, are funnelling push funding into the earliest stages of development: basic research and preclinical trials (Figure 4). Kelly et al.'s ${ }^{27}$ analysis of European public funding of antibacterial research found that $86 \%$ of national-level public funding in antibiotic therapeutics was for basic research. The beneficiaries of this funding tend to be academic research groups, instead of the private SMEs, who often need push funding for translating this research into useable products. ${ }^{45}$ In contrast, large pharmaceutical companies are usually not incentivised to enter the market by push funding, particularly early-stage push funding.

An emphasis on early-stage push funding was initially needed to replenish the complex scientific groundwork and experimental compounds needed to feed into the clinical development phases. However, as more drug candidates move to the later stages of clinical development, there is a critical need for early-stage push funding to be pooled and re-allocated towards late-stage push funding to best ensure that potentially valuable antibiotics make it to market. The persistent overemphasis of early-stage push funding probably reflects, in part, that basic research lends itself to being subdivided into multiple projects that require smaller monetary commitments compared to clinical trials. There are, however, lower success rates of producing antibiotics at this stage than at later stages in the development process. In addition, many of the funders of these initiatives are public funders that can more easily support academic work, which tends to focus on basic research. BARDA and the IMI's COMBACTE should be commended for their commitment and transAtlantic cooperation to actively fund major clinical trials. These two initiatives are the major late-stage push funders on the market. The InnovFin Infectious Disease Facility is another programme that offers some late-stage push funding for clinical trials through risk-shared loans; however, Brogan and Mossialos $^{33}$ raise several concerns regarding the programme's effectiveness. The current backing from these few late-stage push funders is not nearly enough to effectively facilitate antibiotic development.

Based on our assessment, there are limited pull incentives on the market. Pull incentives are largely responsible for funding and supporting the last stages of antibiotic development, including clinical trials, market approval and commercialisation. Pull incentives increase or ensure future revenue through direct outcome-based rewards, such as prizes, or through lego-regulatory incentives, such as expedited market approval procedures. ${ }^{15}$ Large pharmaceutical companies particularly benefit from pull incentives which help guarantee a defined market for their product. These bigger firms need to earn approximately $\$ 800$ million per year in revenues on a compound to consider it profitable. ${ }^{7,46-48}$ SMEs often only need $\$ 100$ to $\$ 200$ million

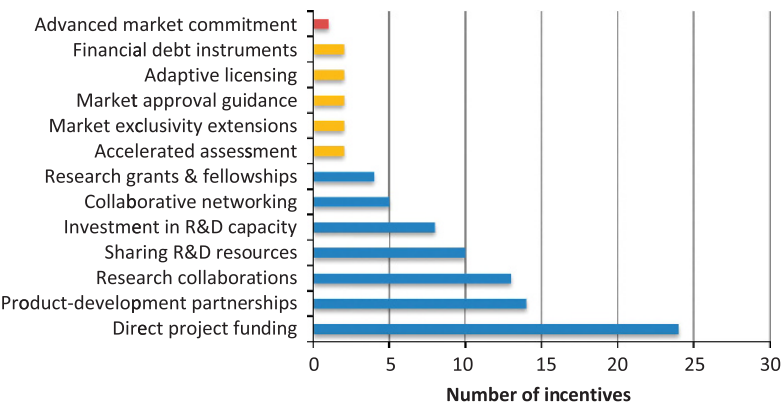

Figure 3 Distribution of incentives employed by antibiotic R\&D initiatives. annually. ${ }^{46}$ However, SMEs can also benefit from pull incentives that guarantee a future return and can help them secure venture capital to fund clinical trials. It is our opinion that the major pull incentives missing from the market are value-based pricing and reimbursement plans, advanced market commitments, tax incentives and large market entry rewards. These could help balance out the current funding support across the antibiotics value chain.

There may be a role for medicines with high global health value, such as antibiotics, to be priced and reimbursed separately from other health technologies. The prices and reimbursement levels of novel antibiotics should ideally reflect the drug's contribution to controlling the global spread of AMR. ${ }^{49}$ Currently, most countries seem to include antibiotics within their wider pricing and reimbursement policies that aim to minimise drug costs and procurement inefficiencies. We understand that determining an accurate premium is methodologically challenging for national drug agencies and must reflect a country's individual health priorities and ability to pay. However, standardised premiums can help realign antibiotic pricing and reimbursement for innovative antibiotics and encourage companies to develop high-value drugs. ${ }^{15}$ In addition, value-based pricing could be used in conjunction with an advanced market commitment to procure and regulate a novel antibiotic's distribution. ${ }^{49}$ The UK Department of Health and the National Institute for Health and Care Excellence are exploring ways to fairly value, price and reimburse novel antibiotics with findings due by early summer 2018. BARDA and GARDP, the only two initiatives that employ a push-pull hybrid of incentives, use advanced market commitments alongside traditional push funding to guarantee a market for certain low-volume antibiotics. This ensures that developers earn a reasonable revenue on their licensed product while purchasers can partially contain prices on high-value antibiotics and have some control over antibiotic consumption.

Our analysis did not identify any tax incentive policies that specifically subsidise firms developing antibiotics. Tax credits, allowances or deferrals are examples of pull mechanisms that can reduce a company's tax liability. ${ }^{15}$ We believe there is a role for coordinated tax incentives in Europe that support firms developing and marketing novel antibiotics. Tax incentives are highly flexible instruments that can be tailored to benefit both SMEs and pharmaceutical companies, as well as target the clinical trial and commercialisation phases. Moreover, tax incentives do not require upfront payments by governments.

Multiple major reports recommend that a programme of market entry rewards is needed to adequately incentivise innovative antibiotic development. ${ }^{1,7,8,47}$ At present, end prizes have only been used to reward development of rapid diagnostic tools for infectious diseases, the largest prize being the US NIH's prize of $\$ 20$ million. ${ }^{8}$ Proposed individual market entry rewards for novel antibiotics range from $\$ 1$ to $\$ 2$ billion per licensed antibiotic. ${ }^{47}$ Awarded antibiotics must meet a pre-specified target product profile and must be marketed according to sustainability and patient access standards. Another sensible recommendation is by Rex and Outterson who propose that market entry rewards could have a baseline prize that is supplemented by innovation bonuses for achieving certain clinical goals. ${ }^{50}$

Given stated goals of producing 10 to 15 novel antibiotics each decade an effective market entry reward programme could cost between $\$ 10$ and $\$ 30$ billion dollars over the next 10 years. ${ }^{47}$ This is a significant sum and the prize values and total reward pool will largely depend on the ability of nations to pool their resources together in a globally governed fund. Such a fund has been recommended in numerous peer-reviewed articles, the AMR Review and BCG's followup report for the German GUARD Initiative. ${ }^{7,51}$ Beyond incentivising 
Table 2 Active initiatives based on their underlying incentives

\begin{tabular}{lcccc}
\hline & $\begin{array}{c}\text { Only push } \\
\text { incentives }\end{array}$ & $\begin{array}{c}\text { Only outcome-based } \\
\text { pull incentives }\end{array}$ & $\begin{array}{c}\text { regulatory } \\
\text { incentives }\end{array}$ & $\begin{array}{c}\text { A hybrid of push- } \\
\text { pull incentives }\end{array}$ \\
\hline $\begin{array}{l}\text { Multi- } \\
\text { lateral }\end{array}$ & 4 & 0 & 0 & 1 \\
EU level & 3 & 0 & 1 & 0 \\
USA & 1 & 0 & 1 & 1 \\
UK & 2 & 0 & 0 & 0 \\
Total & 10 & 0 & 2 & 2 \\
Percent & $71.4 \%$ & $0.0 \%$ & $14.3 \%$ & $14.3 \%$ \\
of total & & & & \\
\hline
\end{tabular}

antibiotic development, this fund could be used as a method of purchasing or licensing out antibiotic patents and jointly procuring the drug on behalf of participating countries. ${ }^{48}$ DRIVE-AB, a 3-year research project funded through the IMI, will be releasing its final report in September 2017. ${ }^{31}$ Among other recommendations, the DRIVE- $A B$ team calls for the implementation of a market entry reward and the report will discuss how to effectively design and implement such a reward.

Despite all the academic literature advocating the need for a large pull incentive programme governed by a global body, there appears to be minimal political willpower, capacity and expertise to bring this strategy to fruition. Instead, international agencies, national governments, NGOs and industry have been independently allocating their funding to the multitude of available R\&D initiatives. Consequently, we are seeing the rise of numerous 'global' initiatives that largely have the same goal: support R\&D of antibiotics. ${ }^{52}$ On top of these international initiatives, each country also has their own array of national programmes. For instance, UK-based government organisations provide direct funding to the JPIAMR, GARDP and Global
Antimicrobial Resistance Innovation Fund, and indirectly to numerous European initiatives such as the EDCTP, DG-RTD and IMI. The UK Cross Research Council Initiative, Global Challenge Research Fund, Newton Fund and NIHR are nationally run initiatives. There is significant risk of duplication of efforts with so many different initiatives receiving interweaving national funding. Moreover, governments are now looking at their own national environments for how to create local pull incentives. However, this may have a limited effect and may not be a strong enough signal to developers that there is a robust market for their products.

At the very least there is a need for a single global governing entity that could coordinate disparate national and international antibiotic R\&D funding at a high level but that allows implementation at a national or organisational level. Such a body could build on existing co-ordination efforts, establish internationally agreed priorities for antibiotic $\mathrm{R} \& \mathrm{D}$, coordinate and streamline existing and new initiatives, foster synergies between stakeholders and integrate R\&D efforts within the wider global AMR strategy. This is not intended to stifle the diversity of approaches needed to stimulate antibiotic innovation, but rather provide a unified direction for these varying approaches. As a bonus, a global governing body would be ideally situated to manage or work alongside a global funding programme for market entry rewards if political momentum gathered action through the G20.

With regards to lego-regulatory pull incentives, both the EMA and Food and Drug Administration individually have several useful mechanisms that expedite approval of high-priority antibiotics if they were to reach the market approval stages. The Trans-Atlantic Taskforce on Antimicrobial Resistance, a collaboration between EU and US regulatory, funding and administrative bodies, is working to harmonise the licensing requirements between the EMA and Food and Drug Administration. ${ }^{42}$ Speeding up the approval process improves a project's NPV and can facilitate timely patient access to new antibiotics. There are, however, several powerful lego-regulatory incentives that are not being utilised including priority review vouchers and transferable intellectual property rights. ${ }^{15}$ If governments

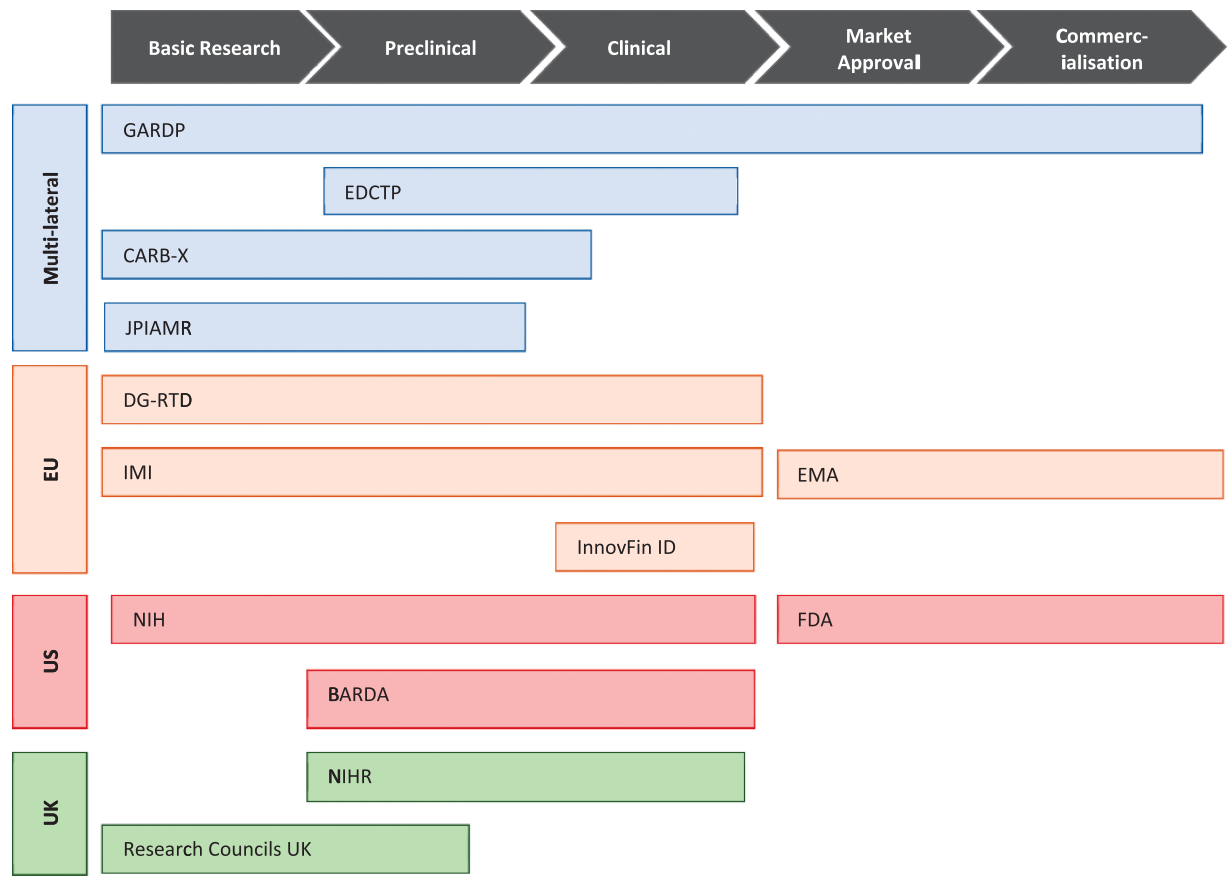

Figure 4 Distribution of multi-lateral, EU, US and UK antibiotic R\&D initiatives across the antibiotic development value chain. 
are not willing to commit to significant outcome-based pull rewards, then priority review vouchers and transferable intellectual property rights may be worth further exploring. The 2017 OHE report identifies transferable intellectual property rights as a promising incentive mechanism. ${ }^{47}$

The final elements that stand out as problematic in the current set of initiatives involves the public health goals of targeting R\&D towards meeting medical needs, facilitating patient access to necessary antibiotics, and sustainable use of existing and new antibiotics. The recent PEW Trust analysis suggests that the majority of antibiotics in the development pipeline do not have activity against a Centre for Disease Control priority pathogen or ESKAPE pathogen. ${ }^{6}$ Some initiativespecific reasons that may contribute to this problem include: multiple initiatives not having explicit links between their incentives and R\&D of high-priority pathogens (Table 1), the lack of coordination among initiatives may be sending mixed signals about which pathogens should be targeted and, finally, the over-reliance on early-stage push funding makes it a challenge to control the direction of private R\&D. The recently released World Health Organisation Priority Pathogens List should now serve as the overarching guide for initiatives in prioritising funding allocation to $\mathrm{R} \& \mathrm{D}$ projects and be tailored to national, regional or local needs. ${ }^{53}$ This list should be dynamic and regularly refreshed in order to minimise the already extensive time lag in antibiotic innovation.

Our assessment also determined that few R\&D initiatives have explicit sustainability and patient access policies. This may be because sustainable medicine use and patient access are traditionally addressed through public health policies. However, it is critically important for R\&D initiatives to support and reiterate other AMR efforts to have an effective global strategy for tackling AMR. ${ }^{54}$ Most initiatives use push incentives, which are usually impractical to link to post-approval conditions regarding marketing practices or distribution of novel antibiotics. ${ }^{45}$ Pull incentives, such as those discussed above, seem more aptly suited to tying R\&D funding with important sustainability and access considerations that only become relevant when the drug is marketed. Numerous strategies have been proposed that specifically integrate sustainability and patient access policies into the $R \& D$ incentive. It seems that the major obstacle of these strategies is their implementation feasibility as they often involve public acquisition of the rights to distribute the antibiotic. This poses a significant risk to industry and major upfront public cost to purchase this responsibility. In-depth discussion of these different strategies is outside the scope of this paper, but will be important to future incentive design and execution.

\section{CONCLUSION}

The global community now recognises the seriousness and growing threat of AMR. Many governmental and non-governmental initiatives are committed to reinvigorating the antibiotic $R \& D$ pipeline. The current set of R\&D incentive programmes in place are laudable and contribute to making antibiotic development an economically viable business model once again. However, there are significant holes in the global incentive scheme that will impede progress towards bringing novel antibiotics to the market. First, most R\&D funding is through early-stage push incentives for basic research and preclinical trials whilst there is a lack of late-stage push incentives for clinical development. Second, there are almost no large-scale pull incentives that meaningfully encourage private investment in clinical trials and eventual commercialisation of antibiotic products. Third, important public health policies that stipulate target product profiles, sustainability requirements and patient access are poorly integrated into R\&D incentive programmes. Lastly, there is minimal overarching guidance and coordination across the active initiatives. This may be the key reason behind the significant gaps in the incentive structure and unaddressed public health priorities. An international co-ordination and governing body enabling national implementation would seem best situated for resolving these policy challenges. At a national level, countries need to individually adjust their funding commitment to spurring antibiotic innovation in a way that more accurately reflects the unrelenting global emergency of AMR. The time has come for high-level commitments to be turned into real tangible actions by all sectors.

\section{CONFLICT OF INTEREST}

The authors declare no conflict of interest.

1 The Review on Antimicrobial Resistance. Antimicrobial resistance: tackling a crisis for the health and wealth of nations, London UK, 1-20, https://amr-review.org/sites/default/ files/AMR\%20Review\%20Paper\%20-\%20Tackling\%20a\%20crisis\%20for\%20the\% 20health\%20and\%20wealth\%20of\%20nations_1.pdf (2014).

2 Rex, J. H. et al. A comprehensive regulatory framework to address the unmet need for new antibacterial treatments. Lancet Infect Dis. 13, 269-275 (2013).

3 Outterson, K., Powers, J. H., Daniel, G. W. \& McClellan, M. B. Repairing the broken market for antibiotic innovation. Health Aff (Millwood) 34, 277-285 (2015).

4 Spellberg, B. The future of antibiotics. Crit. Care 18, 228 (2014).

5 The Boston Consulting Group. Breaking through the wall: enhancing research and development of antibiotics in science and industry, Berlin DE, 1-84, https://www. bundesgesundheitsministerium.de/fileadmin/Dateien/5_Publikationen/Gesundheit/Berichte/GUARD_Follow_Up_Report_Full_Report_final.pdf (2017).

6 Antibiotics Currently in Clinical Development http://www.pewtrusts.org/ /media/assets/ 2017/05/antibiotics-currently-in-clinical-development-03-2017.pdf?la = en (2017).

7 Stern, S., C., S., Franken, L., Voller, S., Rentmeister, H. \& Grosch, B. A Call for Concerted Action on Antibiotics Research and evelopment, The Boston Consulting Group, Berlin, (2017).

8 Renwick, M. J., Simpkin, V. \& Mossialos, E. Targeting innovation in antibiotic drug discovery and development: the need for a one-health, one-Europe, one-world framwork. European Observatory on Health Systems and Policies, London, UK, Health Policy Series No. 45, 1-133, ISBN 9789289050401 (2016).

9 Butler, M. S., Blaskovich, M. A. \& Cooper, M. A. Antibiotics in the clinical pipeline in 2013. J. Antibiot. (Tokyo) 66, 571-591 (2013).

10 Chopra, I. et al. Treatment of health-care-associated infections caused by Gramnegative bacteria: a consensus statement. Lancet Infect. Dis. 8, 133-139 (2008).

11 BEAM Alliance. BEAM Alliance position paper: key actions to reinvigorate investment and R\&D in the antibacterial field now, Paris FR, 1-9, https://beam-alliance.eu/assets/ 2015-Position-Paper.pdf (2015).

12 Mendelson, M. et al. A global antimicrobial conservation fund for low- and middleincome countries. Int. J. Infect. Dis. 51, 70-72 (2016).

13 Political Declaration of the high-level meeting of the General Assembly on antimicrobial resistance http://www.un.org/ga/search/view_doc.asp?symbol=A/71/L.2\&referer =/english/\&Lang =E (2016).

14 Interagency Coordination Group on Antimicrobial Resistance. https://www.un.org/sg/en/ content/sg/personnel-appointments/2017-03-17/interagency-coordination-group-antimicrobial-resistance (2017).

15 Renwick, M. J., Brogan, D. M. \& Mossialos, E. A systematic review and critical assessment of incentive strategies for discovery and development of novel antibiotics. J. Antibiot. (Tokyo) 69, 73-88 (2016).

16 Joint Programming Initiative on Antimicrobial Resistance, http://www.jpiamr.eu (2017)

17 First Joint Call: innovative approaches to address antibacterial resistance http://www. jpiamr.eu/activities/joint-calls/first-joint-callresult/ (2014).

18 Global Antibiotic Research \& Development Partnership (GARDP), http://www.dndi.org/ diseases-projects/gardp/ (2017).

19 CARB-X, http://www.carb-x.org (2017)

20 Outterson, K. et al. Accelerating global innovation to address antibacterial resistance: introducing CARB-X. Nat. Rev. Drug Discov. 15, 589-590 (2016).

21 US Centers for Disease Control and Prevention. Antibiotic resistance threats in the United States, 2013, Atlanta US, 1-114, https://www.cdc.gov/drugresistance/threatreport-2013/index.html (2013).

22 CARB-X. CARB-X injects up to $\$ 48$ million to accelerate first powered by CARB-X portfolio of drug discovery and development projects to tackle antibiotic resistance http://www.carb-x.org/press (2017).

23 European and Developing Countries Clinical Trials Partnership. Annual Report 2014 The Hague NL, 1-76, http://www.edctp.org/annualreport2014/EDCTP_Annual_Report_2014_-_EN.pdf (2014).

24 The Review on Antimicrobial Resistance. Tackling a global health crisis: initial steps, London UK, 1-22, https://amr-review.org/sites/default/files/Report-52.15.pdf (2015). 
25 UK-China ties flourish at 2016 High Level People to People Dialogue, https://www.gov. uk/government/news/uk-china-ties-flourish-at-2016-high-level-people-to-people-dialogue (2016).

26 EC. Antimicrobial drug resistance https://ec.europa.eu/research/health/index.cfm?pg= area\&areaname $=$ amdr $(2017)$

27 Kelly, R., Zoubiane, G., Walsh, D., Ward, R. \& Goossens, H. Public funding for research on antibacterial resistance in the JPIAMR countries, the European Commission, and related European Union agencies: a systematic observational analysis. Lancet Infect. Dis. 16, 431-440 (2016).

28 EC. Better use of antibiotics-1 million euros, http://ec.europa.eu/research/horizonprize/ index.cfm?prize = better-use-antibiotics (2017).

29 Kostyanev, T., Bonten, M. J., O'Brien, S. \& Goossens, H. Innovative medicines initiative and antibiotic resistance. Lancet Infect. Dis. 15, 1373-1375 (2015).

30 Kostyanev, T. et al. The innovative medicines initiative's new drugs for bad bugs programme: European public-private partnerships for the development of new strategies to tackle antibiotic resistance. J. Antimicrob. Chemother. 71, 290-295 (2016).

31 Drive-AB Official Website, http://drive-ab.eu/.

32 European Investment Bank. InnovFin Infectious Disease, http://www.eib.org/attachments/documents/innovfin infectious diseases flysheet_en.pdf (2015).

33 Brogan, D. M. \& Mossialos, E. A critical analysis of the review on antimicrobial resistance report and the infectious disease financing facility. Global Health 12, 8 (2016).

34 Billington, J. K. The ABCs of the US Broad Spectrum Antimicrobials Program: antibiotics, biosecurity, and congress. Health Secur. 13, 349-354 (2015).

35 Eichberg, M. J. Public funding of clinical-stage antibiotic development in the United States and European Union. Health Secur. 13, 156-165 (2015).

36 Office of the Assistant Secretary of Preparedness and Response. HHS forms strategic alliance to develop new antibiotics approach provides a pipeline of new drugs rather than a single medical countermeasure. US Department of Health and Human Services, http://www.phe.gov/Preparedness/news/Pages/strategic-alliance-130522.aspx (2013).

37 Office of the Press Secretary, The White House. Executive Order No. 13676 Combating Antibiotic-Resistant Bacteria (2014).

38 MRC Tackling AMR-a cross-council initiative. https://www.mrc.ac.uk/research/initiatives/antimicrobial-resistance/tackling-amr-a-cross-council-initiative/ (2016).

39 RCUK. Global Challenge Research Fund http://www.rcuk.ac.uk/funding/gcrf/ (2017).

40 Newton Fund. http://www.newtonfund.ac.uk (2017).

41 National Institute for Health Research. Antimicrobial resistance http://www.nihr.ac.uk/ research-and-impact/research-priorities/antimicrobial-resistance.htm.

42 Transatlantic Taskforce on Antimicrobial Resistance. Recommendations for future collaboration between the US and EU, Atlanta US, 1-86, https://www.cdc.gov/ drugresistance/pdf/tatfar-progress_report_2014.pdf (2014).

43 Pew Charitable Trusts. GAIN: how a new law is stimulating the development of antibiotics http://www.pewtrusts.org/en/research-and-analysis/issue-briefs/2013/11/07/ gain-how-a-new-law-is-stimulating-the-development-of-antibiotics/ (2013).
44 Pew Charitable Trusts. LPAD: a regulatory pathway to develop antibiotics and fight drugresistant infections http:/www.pewtrusts.org/en/research-and-analysis/q-and-a/2015/06/ Ipad-a-regulatory-pathway-to-develop-antibiotics-and-fight-drug-resistant-infections (2015).

45 Mossialos, E., Edwards, M. C., Berenson, S., Gemmill-Toyama, J. \& Brogan, M. D. Policies and Incentives for Promoting Innovation in Antibiotic Research (World Health Organisation, London, UK, 2010).

46 Monnet, D. L. Antibiotic development and the changing role of the pharmaceutical industry. Int. J. Risk Saf. Med. 17, 133-145 (2005).

47 Ferraro, J. S., Towse, A. \& Mestre-Ferrandiz, J. Incentives for New Drugs to Tackle AntiMicrobial Resistance, Office of Health Economics (London, UK, 2017).

48 The Review on Antimicrobial Resistance. Securing new drugs for future generations: the pipeline of antibiotics, London UK, 1-44, https://amr-review.org/sites/default/files/ SECURING\%20NEW\%20DRUGS\%20FOR\%20FUTURE\%20GENERATIONS\% 2OFINAL\%20WEB 0.pdf (2015).

49 Brogan, D. M. \& Mossialos, E. Incentives for new antibiotics: the Options Market for Antibiotics (OMA) model. Global Health 9, 58 (2013).

50 Rex, J. H. \& Outterson, K. Antibiotic reimbursement in a model delinked from sales: a benchmark-based worldwide approach. Lancet Infect. Dis. 16, 500-505 (2016).

51 O'Neill, J. Tackling Drug-Resistant Infections Globally: Final Report and Recommendations (2016).

52 Hoffman, S. J. et al. Strategies for achieving global collective action on antimicrobial resistance. Bull. World Health Organ 93, 867-876 (2015).

53 WHO. Global Priority List of antibiotic-resistant bacteria to guide research, discovery, and development of new antibiotics, 1-7 (World Health Organisation, 2017).

54 Kesselheim, A. \& Outterson, K. Improving antibiotic markets for long term sustainability. Yale J. Health Pol. Law Ethics 11, 101-168 (2013).

This work is licensed under a Creative Commons Attribution-NonCommercial-ShareAlike $\quad 4.0$ International License. The images or other third party material in this article are included in the article's Creative Commons license, unless indicated otherwise in the credit line; if the material is not included under the Creative Commons license, users will need to obtain permission from the license holder to reproduce the material. To view a copy of this license, visit http://creativecommons.org/licenses/by-nc$\mathrm{sa} / 4.0 /$

(C) The Author(s) 2017

Supplementary Information accompanies the paper on The Journal of Antibiotics website (http://www.nature.com/ja) 